\title{
AS LEIS №. 10.639/03 E №. 11.645/08: DOS MARCADORES SOCIAIS DA DIFERENÇA À FORMAÇÃO DE PROFESSORES INDÍGENAS E NEGROS
}

\author{
Vilma Aparecida Pinho ${ }^{1}$, Francilene de Aguiar Parente ${ }^{2}$ \\ ${ }^{1}$ Doutora em Educação pela Universidade Federal Fluminense - UFF. Docente da Universidade Federal do Pará - UFPA, \\ Altamira, PA. E-mail: vilmaaparecidadepinho@gmail.com \\ ${ }^{2}$ Doutora em Antropologia pela Universidade Federal do Pará - UFPA. Docente da Universidade Federal do Pará - \\ UFPA, Altamira, PA.
}

\section{RESUMO}

Este artigo aborda a formação de professores no contexto da educação diferenciada no curso de Etnodesenvolvimento da Universidade Federal do Pará (UFPA). Baseado na Pedagogia da Alternância, o curso é voltado para povos indígenas, quilombolas, negros e comunidades tradicionais. $O$ estudo discute a importância desses sujeitos como agentes sociais para a proposição da transformação em suas coletividades e comunidades, nos diferentes espaços que ocupam e por onde circulam. O não lugar do indígena, do negro e do quilombola vivido na educação básica por nossos egressos demarca a força ideológica de uma epistemologia que obscurece a compreensão de sujeitos etnicamente diferenciados e da diversidade como perspectiva e lugar centralizado para pensar as relações sociais e viver em sociedade. Por meio da metodologia qualitativa, a pesquisa com foco nas trajetórias de vida indica que, na formação de professores, a perspectiva da educação para a diversidade tem sido observada na prática como estratégica desses docentes e das comunidades para o exercício do respeito à diferença. Além disso, esses indivíduos têm sido representados como professores, pesquisadores, articuladores políticos, dentre outras funções e papéis sociais.

Palavras-chave: Formação de professores. Educação diferenciada. Sujeitos. Diversidade cultural.

LAWS №. 10.639 / 03 E No. 11.645 / 08: FROM THE SOCIAL MARKERS OF THE DIFFERENCE TO THE TRAINING OF INDIGENOUS AND BLACK TEACHERS

\begin{abstract}
This article approaches the training of teachers in the context of differentiated education in the Ethnodevelopment course of the Federal University of Pará (UFPA). Based on the Pedagogy of Alternation, the course under analysis is aimed at differentiated public such as indigenous people, quilombolas, black and traditional communities. The study discusses the importance of these subjects as social agents for the proposition of transformation in their collectivities and communities, in the different spaces they occupy and through which they circulate. The non-place of the indigenous, the black and the quilombola in basic education by our graduates demarcates the ideological force of an epistemology that obscures the understanding of ethnically differentiated subjects and diversity as a perspective and centralized place to think about social relations and life in society. Through the qualitative methodology, research focusing on life trajectories indicates that in teacher training, the perspective of education for diversity has been observed as a strategy for teachers and communities to exercise respect for the difference. In addition, these individuals have been represented as teachers, researchers, political articulators, among other functions and social roles.
\end{abstract}

Keywords: Teacher training. Differentiated education. Subjects. Cultural diversity.

\section{INTRODUÇÃO}

Pensamos a formação de professores indígenas, negros e quilombolas de maneira complexa, considerando suas experiências desde a Educação Básica na escola, na família e nos grupos comunitários até a formação em nível 
superior na universidade. Este artigo aborda, especialmente, a formação de professores no contexto da educação diferenciada no curso de Etnodesenvolvimento, curso de Licenciatura e Bacharelado em nível de graduação ${ }^{1}$, voltado para público diferenciado (povos indígenas, quilombolas, negros e comunidades tradicionais), com vistas à formação de etnoeducadores, que "atendam às necessidades dos povos e comunidades tradicionais", para a atuação na área de conhecimento das Ciências Humanas, nos anos finais do ensino fundamental e ensino médio (UFPA/PPC, 2009).

O curso é abrigado no Campus Universitário de Altamira/UFPA da Universidade Federal do Pará (UFPA) e a importância desses sujeitos como agentes sociais para a proposição da transformação em suas coletividades e comunidades, nos diferentes espaços que ocupam e por onde circulam. Por agentes sociais compreende-se, à luz de Almeida (2008, p. 38) "[...] sujeitos sociais com existência coletiva, incorporando pelo critério político-organizativo uma diversidade de situações correspondentes".

Vamos considerar a transformação dos alunos egressos do curso como um fato de libertação e que, mediante as experiências com conteúdos de formação na educação diferenciada, puderam se revisitar e desenvolver conhecimento de si com bases em outros patamares de consciência de mundo, de cultura, de suas histórias em relação às histórias do Brasil, de ideologias e de mecanismos das construções de concepções sobre a humanidade.

As narrativas orais e escritas dos educandos e egressos do curso, relatadas durante as atividades curriculares do curso de Etnodesenvolvimento, no tempo universidade, tais como: Antropologia e Diversidade; Memória, oralidade e performances; e Práticas educacionais, saberes e etnoeducação; e no tempo comunidade, deslindam situações de negação de construção de si com base corporal e cultural, pois se construíram na estratégia de sobrevivência às situações de preconceito, discriminação e racismo que enfrentavam no

\footnotetext{
${ }^{1}$ Criado a partir da Resolução N. 3.860, de 22 de maio de 2009, com vagas para 45 discentes e entrada a cada dois anos. Em 2011, 2013 e 2015 entraram, respectivamente, a primeira, a segunda e a terceira turmas do curso; em 2016, uma turma foi flexibilizada para o Campus de Soure, na Ilha do Marajó. O curso conta atualmente com seis docentes vinculados e inúmeros parceiros dos campi da UFPA em Altamira e Belém, além de outros tantos que buscam o direito à educação a todos os cidadãos previsto em nossa Constituição, e a educação diferenciada aos tidos como diferentes.
}

cotidiano escolar. As experiências étnicas e raciais constam nas suas consciências como adversidades, negação e revelação de si como sujo, desqualificado e inferior.

Um não lugar, como discute Bhabha (2005) a partir de Franz Fanon, eis que o colonialismo e a colonialidade adquirem forças históricas, sociais e ideológicas que atravessam gerações mediante a desigualdade de acesso aos direitos sociais fundamentais e também pela construção de si mergulhado nas parafernálias dos estereótipos raciais e étnicos.

O não lugar do indígena, do negro e do quilombola vivido na educação básica por nossos egressos demarca a força ideológica de uma epistemologia que obscurece a compreensão de sujeitos etnicamente diferenciados e da diversidade como perspectiva e lugar centralizado para pensar as relações sociais e viver em sociedade.

\section{A questão dos estudos e das políticas culturais - ação afirmativa de acesso e conteúdos de formação}

Podemos dizer que no Brasil em geral e na UFPA, houve e está ainda em implementação uma política cultural da diferença na qual os indígenas, negros e quilombolas ingressam mediante o impulso criado pela (re)afirmação da identidade, por políticas diferenciadas de acesso e por currículos escolares que têm por eixo a diversidade cultural. $O$ que está em jogo no processo de formação de professores é uma estratégia cultural, no interior do qual se efetua o deslocamento das disposições de poder. Os indígenas, os negros e os quilombolas (sujeitos marcados pela violência colonial e neocolonial) são enfatizados na formação pelas suas contestações e culturas transgressivas, coletivas e inter/multiculturais.

É importante para os estudos de construção de identidade docente um projeto de conhecimento que torne visualizável a resistência agressiva à diferença na construção dos estados/nações; a tentativa de restaurar o cânone da civilização ocidental eurocêntrica; os ataques diretos e indiretos ao multiculturalismo e o retorno às grandes narrativas da história em contraste aos sujeitos reais, suas experiências, suas subjetividades. Busca-se o descentramento da narrativa ocidental pelo conhecimento e 
reconhecimento da importância das tradições diaspóricas indígenas, negras e quilombolas. ${ }^{2}$

As vozes dos egressos indicam que houve um tensionamento dos discursos oficiais em prol de outros discursos e de outras circunstâncias que envolviam a diversidade de povos e de culturas. Dessa forma, podemos afirmar, baseadas em Hall (2003), que houve uma tomada de consciência de posição, ou seja, desenraizamentos das epistemologias e tendências universalizantes que se dirigem aos caminhos da reificação da dinâmica e da dialética da história. Buscamos dessa forma um rompimento com o reducionismo economicista do marxismo clássico, conforme a crítica teórica dos estudos culturais, com o engajamento dos alunos em experiências vividas de tal forma que as subjetividades se sintam autorizadas pelo reconhecimento de si como parte da história.

As vozes que emergem do processo de formação indicam uma tradução e negociação que, para Bhabha (2005), significa uma "luta liberatória" de continuidades e de constâncias da tradição nacionalista forjadas no escopo do colonialismo. Nesse sentido,

[...] Eles estão livres agora
para negociar e traduzir
suas identidades culturais
na temporalidade
descontínua, intertextual,
da diferença cultural. [...]
O povo [os egressos do
curso] é agora o próprio
princípio de reorganização
dialética e constrói sua
cultura a partir do texto
nacional traduzido para
formas ocidentais
modernas de tecnologia
de informação, linguagem,
vestimenta. O novo lugar
de enunciação político e
histórico transforma os
significados da herança
colonial nos signos
liberatórios de um povo
livre e do futuro (BHABHA,
2005 , p. 68).

Trata-se da articulação da diferença cultural "que acompanha a assimilação de contrários [e] cria a instabilidade oculta que pressagia poderosas mudanças culturais" (Idem,

\footnotetext{
${ }^{2}$ Para maiores informações sobre as migrações compulsórias, que denominamos diáspora à luz de Benbassa (2010), entre os indígenas, consultar Beltrão e Lopes (2014).
}

p. 68). O reconhecimento teórico do espaço-cisão da enunciação é capaz de provocar mudanças e caminhos para uma compressão das culturas, não como um exótico multiculturalismo, mas da inscrição no inter (nós e outros) e outros de nós no hibridismo cultural, "o fio cortante da tradução e negociação, o entre-lugar" (BHABHA, 2005, p. 69).

Assim, queremos expressar que esses sujeitos da formação desenvolveram capacidades de compreender a cultura como "diferentes estruturas de integração simbólica" (Idem, 2005, p. 68). Isso é importante na medida em que o conhecimento de si desempenha um papel crucial para os sujeitos, que uma vez conscientes da fluidez do movimento e da dinâmica histórica na qual estão inseridos, "[...] garantem que o significado e os símbolos da cultura não tenham unidade ou fixidez, pois os mesmos signos são apropriados, traduzidos, re-historicizados e lidos de outro modo" (BHABHA, 2005, p. 69).

$A$ formação de professores no que tange ao ensino superior e à educação diferenciada contrapõe a ideia de aprendizagem como aquisição de habilidades técnicas pelo conhecimento de conteúdos, pois cremos que a formação realmente transformadoras colocam em dúvida as certezas e as ambivalências. Nisso, promovem as representações e organizações de mundo, modos de fazer e de ser nas diferentes sociedades para o reconhecimento de diversas identidades.

A identidade cultural na profissionalização docente tornou-se uma importante categoria de análise para a compreensão de formação, prática, concepções e identidades docentes. Afirmam Hypólito et al (2003) que é necessária uma flexibilização teórica para a análise do trabalho docente tendo em vista a complexidade de forças materiais e não materiais que se articulam nos processos concretos do trabalho profissional.

Observe-se que gênero e classe social são categorias bastante utilizadas para estudar a profissão docente, dadas as ambivalências entre a profissionalização e a proletarização. Mas a raça/etnia também se torna importante devido às negociações e interesses que há em torno dessas dimensões humanas que se refletem na prática docente. Assim,

[...] [O]s professores e as professoras possuem interesses e identidades ligadas a gênero, 
raça/etnia e classe social. As contradições existentes nas lutas sociais e políticas de negação ou de afirmação das culturas das minorias e de diferentes grupos étnico-raciais, em relação com as classes sociais, envolvem também os/as docentes. Os professores e as professoras, ao verem-se obrigados a padronizar o ensino desde a perspectiva de uma cultura padrão - centrada na masculinidade, na branquidade, no cristianismo e no eurocentrismo, vêem-se diante de relações políticas de poder que envolvem seus próprios interesses de gênero, de classe social e étnicoraciais (HYPÓLITO et. al., 2003, p. 125).

Interessante destacar ainda que "diferentes regimes do eu e formas de subjetivação concorrem para essas definições e lutam pela imposição de significados acerca de quem os professores e as professoras devem ser em determinadas conjunturas" (HYPÓLITO et. al, 2003, p. 126). A formação de professores, nesse sentido, é uma complexidade.

\section{Experiências indígenas, negras e quilombolas na educação básica: Etnodesenvolvimento e trajetórias como metodologia}

Os indígenas, negros e quilombolas que acessaram o ensino superior via política de ação afirmativa no curso de Etnodesenvolvimento na UFPA trazem consigo relatos de trajetórias na educação básica que têm como marca a negação de suas identidades étnicas e, consequentemente, de si, na medida em que elas representam quem são.

Para Bourdieu (1998), a trajetória do sujeito não pode ser percebida de forma individual porque ao longo do tempo ele entra em contato com diversos grupos sociais e coletivos étnicos e raciais, cujos objetivos, ações, vivências e representações são compartilhadas com esse indivíduo. Por mais que a trajetória possa ser pensada como construção individual, existem recorrentes interfaces que se encontram em determinados momentos, que contribuem na composição das histórias de vida que se apresentam individualmente.

Essas negações, compartilhadas entre sujeitos étnica e racialmente diferenciados, fazem parte das trajetórias vividas por indígenas, negros e quilombolas nas escolas. Elas se materializam desde o excesso de burocracia, universalizante, diga-se de passagem, da instituição escolar que, muitas vezes, impede o ingresso de determinados sujeitos de nossa sociedade na escola, como os documentos civis exigidos no momento da matrícula para povos e comunidades cujo contato com elementos básicos da cidadania se impõe na medida em que o desejo de acessar a escola cresce entre crianças, jovens e seus familiares, como informa Maíra: ${ }^{3}$

[...] O ingresso na escola
foi muito difícil, primeiro
começamos a estudar com
uma vizinha, devido nós
não entendermos muito o
português, desse modo
fomos nos adaptando a
pronunciar o português;
depois de uns seis meses
minha mãe resolveu nos
matricular na escola.
Então apareceu outro
problema: não tínhamos
registro de nascimento,
nessa época a mãe não
podia registrar o filho sem
a presença do pai. Nesse
meio tempo, meu pai
tinha saído da firma e
trabalhava nos garimpos,
o que dificultou o
processo da retirada desse
registro (educadora
indígena da etnia Xypaia).

A língua também tem sido apontada como fator de exclusão. Como visto, a língua precisa de muito cuidado, mesmo em se tratando de indígenas que não moravam em aldeias no momento em que vieram para a cidade, como o caso citado, o que demonstra que, independente de se falar ou não a língua materna de seu povo, a língua falada pelo grupo não é o português homogeneizado da escola.

\footnotetext{
${ }^{3}$ Os nomes são fictícios para a preservação das identidades das pessoas com quem dialogamos ao longo da coleta de dados, mas os nomes étnicos correspondem aos de seus respectivos povos.
} 
Não compreender ou não falar a língua portuguesa em acordo com as convenções socialmente aceitas pelas instituições tem sido apresentado por indígenas, negros e quilombolas que vivem na cidade ou estudam nas escolas da área urbana ou rural dos municípios como excludente desses sujeitos e coletividades no ambiente escolar. Em uma das narrativas coletadas, a marca da diferença é tão evidente que a educanda negra faz referência à sua fala como "pretoguês".

Ela narra essa situação dando ênfase ao fato de que a fala ou grafia "incorreta" de uma palavra não significa ignorância, mas marca da identidade de um povo, pois se sabe que no ato de nomear há relações de poder imbuídas nas representações que a elas estão associadas e, acrescentamos, resistência aos universalismos e às padronizações impostas por quem detém o poder da cultura.

Todorov (1993) argumenta que o ato de dar sentido ao "novo mundo" foi uma das estratégias acionadas por Colombo na pretensa descoberta da América, negando os sentidos produzidos pelos nativos que aqui viviam. Ao dar nomes imprimiu a sua representação de mundo baseada nos valores europeus, considerados superiores frente aos demais; hierarquizou, tornou desigual com a pretensão de "civilizar" para torná-los humanos e homogeneizar formas de vida.

Com isso, percebemos o quanto a escola que se propõe inclusiva reproduz as desigualdades sociais, nega a diversidade existente em nossas sociedades e relega os sujeitos etnicamente diferenciados à própria sorte das redes sociais que constroem para se manterem na mesma sociedade que os exclui, como observaremos no próximo relato de Maíra:

[...] Certo dia, essa senhora [dona do Cartório do 3 o oficio à época], conversando com minha mãe, quis saber porque nós não estávamos na escola, minha mãe respondeu que nós não tínhamos registro, e ela se propôs a fazer o nosso registro sem a presença do meu pai, quando ele voltasse do garimpo iria ao Cartório assinar esses documentos, para que nós ficássemos com 0 sobrenome do pai e da mãe no registro. Assim ocorreu, mas o tempo passou e meu pai nunca foi ao Cartório assinar os papeis e nós ficamos somente com o nome de registro de nossa mãe (educadora indígena da etnia Хураia).

Ao mesmo tempo em que a narrativa traz elementos das estratégias empreendidas para acessar a escola por parte de grupos indígenas, o que demonstra a importância dada à escolarização por eles, também deixa entrever parcela das situações a que os povos indígenas estão suscetíveis vivendo em áreas urbanas e que os vulnerabiliza frente a outras situações.

Por exemplo, no caso em análise, havia uma relação de trabalho informal estabelecida entre a mãe da indígena e a dona do cartório, em outras palavras, de exploração da mão de obra em jornadas exaustivas para a execução de serviços domésticos; ademais, existia uma vontade de que os filhos indígenas acessassem a escola. Para tanto, utilizou-se do famoso jeitinho brasileiro, ${ }^{4}$ promovido pela proprietária do cartório, para que as crianças e jovens pudessem estudar.

Essa "ajuda" gerou certa obrigatoriedade de retribuição do "favor" por parte da família indígena em vários níveis e gerações, especialmente nos trabalhos domésticos, de forma que ainda hoje acreditam e creditam a essa senhora o fato de terem conseguido acessar a educação escolar e a agradecem como a uma santidade, sem perceber que houve uma troca de favores, conforme "mandam" os usos do jeitinho.

Mas os desafios não se encerravam na garantia do ingresso, como mostrado anteriormente. Para além da dificuldade da língua, havia entraves de toda ordem, como a alimentação escolar, com produtos enlatados para pessoas que consumiam frutas e comida independente do horário da refeição; a convivência com outras pessoas com quem não estavam acostumadas, mas essencialmente a

\footnotetext{
4 O jeitinho brasileiro tem sido estudado como mecanismo universalmente conhecido pelo brasileiro para navegar socialmente e se desviar das normas burocráticas e individualizantes de nossa sociedade (BARBOSA, 2006). Os usos do jeitinho implicam quase sempre a ideia de que "uma mão lava a outra", um favor que o indivíduo irá requerer quando necessário.
} 
identidade étnica que não era reconhecida pelos demais que as cercavam.

Em outra das narrativas, a indígena comentou que não se separava dos irmãos na escola: "andávamos sempre juntos. Para onde um ia, os outros íam junto". Estar junto era uma forma de proteção em relação ao ambiente estranho em que se transformava a escola para eles, o que nos leva a pensar que o processo de inclusão precisa ser entendido de maneira mais ampla porque estar na escola, acessá-la, não necessariamente significa estar incluso; a permanência naquele espaço precisa fazer parte da discussão sobre inclusão, assim como o respeito à diversidade. Portanto, a educação escolar desejada era/é vivida como espaço das relações entre diferentes, espaço de fronteira, uma fronteira étnica, como discutido por Barth (2000).

Para ele, as escolas se constituem em espaços fronteiriços, que podem ou não ter contrapartidas territoriais, em que os sujeitos entram em interação e diferentes identidades se constituem no cruzamento hibridizante dessas relações cotidianas; por isso, esse é um espaço em permanente processo de construção social das diferenças. Dentre as várias identidades que estão sendo produzidas e mantidas, a étnica tem a especificidade de se apresentar a partir da crença subjetiva de ser e pertencer a uma comunidade de origem comum.

Logo, o ambiente tornou-se estranho não somente porque era espaço novo na vida deles, mas acima de tudo por se apresentar como o lugar do enquadramento de comportamentos e modos de vida, disciplinamento de pensamentos e corpos. Estar na escola é descrito como "difícil" porque ao mesmo tempo em que eram apontados como "diferentes" dos demais, não tinham sua diferença étnica reconhecida na alteridade. Dessa forma, ficavam sempre na condição de liminaridade. Ou um não lugar.

Tainá, afirma que "[...] a gente só permaneceu na escola porque queria muito. Em tudo a gente não era aceito, às vezes porque não éramos indígenas, às vezes porque não éramos considerados brancos" (educadora indígena da etnia Xypaia). Em outras palavras, afirmavam-se indígenas e não eram reconhecidos como tal porque não carregavam no corpo o estereótipo construído socialmente, não viviam nas aldeias e nem falavam a língua materna; entretanto, também não eram aceitos como "iguais" aos demais alunos pois não eram vistos dessa forma.
Como resistir? A resistência, então, se deu pela apropriação da descendência como categoria identificatória ${ }^{5}$. O discurso da descendência utilizado por não indígenas com o propósito de apagar a identidade étnica foi ressignificado pelos indígenas na escola para a manutenção da diferença naquele contexto social.

A descendência indígena, para esse grupo, marcada essencialmente pelo sangue e pela convivência com os mais velhos, como sinais diacríticos, passou a ser acionada como a identidade dos povos indígenas que viviam na cidade de Altamira até a entrada na universidade.

Muito embora os indígenas tenham resistido e mantido a identidade étnica por meio da ressignificação da ideia da descendência, não é possível negar que esse era e é um trabalho cotidiano de afirmação frente ao discurso da "mistura" que está impresso no uso desse termo desde a construção da ideia de nação. No caso em análise, por mais que o designativo tivesse sido construído a partir da ideia da "mistura", era utilizado pelos indígenas como resultado das situações sociais $^{6}$ vividas pelos grupos que se encontram na cidade, da identidade construída nas relações sociais estabelecidas no presente de onde partem para rever o passado, como discutem Weber (2014) e Barth (2000), cujas fronteiras estão sempre em movimento.

Essas histórias podem ser multiplicadas em relação aos indígenas que vivem na cidade de Altamira, mas ficaremos apenas com estas que demonstram as estratégias acionadas para a vivência na cidade e ingresso e permanência na escola.

Como visto, vários indígenas e negros narram episódios de sofrimento no ambiente escolar e o quanto isso marcou sua trajetória na escola durante a educação básica, mas também a de vida. Entre os negros, a situação não era muito diferente. Dandara, uma educadora negra, relata que ela e os irmãos tiveram "uma infância muito boa, no domínio do lar; mas na escola sofremos muito preconceito, acho que foi a fase mais difícil da nossa vida na infância, pelo menos para mim foi". A escola aparece nas narrativas sempre como um dos momentos mais difíceis da vida,

\footnotetext{
${ }^{5}$ Para maiores informações sobre o assunto em relação aos povos indígenas que vivem na cidade de Altamira/PA, consulte Parente (2016).

6 Tomando os estudos de Antropologia Política realizados por Gluckman (2010) como referência, situação social é uma noção que traz a ideia de que os diversos atores envolvidos estão em relação, por vezes em interdependência, em decorrência de determinadas ações e eventos historicamente constituídos.
} 
dos encontros e desencontros, da descoberta da diferença.

A novidade da educação escolar era acompanhada de expectativas positivas, que logo se transformaram em frustrações para a menina negra, que informa: "nos primeiros dias de aula, tudo era novo para mim e eu não sabia como seria ruim; enfrentando um mundo desconhecido sem saber se defender e nem a quem recorrer: era um inferno todos os dias" (Dandara, educadora negra). Observe que as experiências escolares vividas como preconceito se fundamenta na concepção de Nogueira (2006) como preconceito "de marca", àquele cujos estereótipos raciais se valem da "marca", ou seja, dos significados da diferença como desigualdade e hierarquia.

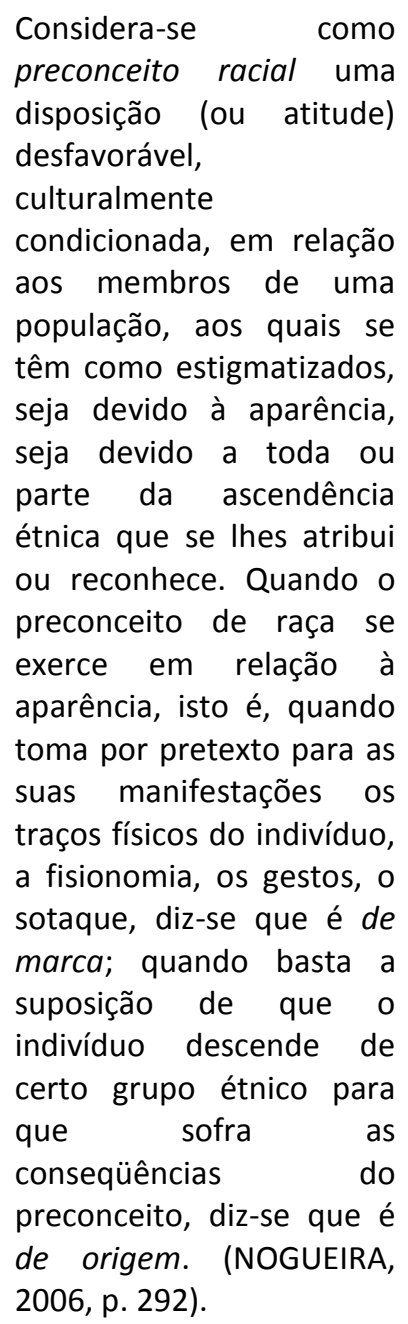

A fala que expressa o preconceito e a discriminação étnico-raciais vividas, deixa entrever uma das principais estratégias utilizada nesse tipo de situação e muito associada ao jeitinho brasileiro: a individualização do conflito para não dar mostras do sentido coletivo da ação. Ou seja, a ação é recaída totalmente sobre o sujeito como forma de desassociá-lo do preconceito étnico e/ou racial se que carrega em si. Dessa forma, ela seria esvaziada do sentido preconceituoso porque estava atrelada ao sujeito e não à sua raça e/ou etnicidade.

Isso fica muito evidente quando Dandara fala que "desejava muito que chegasse outra menina negra para dividir o sofrimento comigo, pelo menos eu não ia ser a única a levar pancadas e apelidos maldosos". Importante salientar vários aspectos do registro: [1] Dandara chama atenção para o fato de ser alvo de chacota por parte de seus colegas que a apelidavam de "neguinha do Codó, cabelo de Bombril, urubu", dentre outros; e [2] gostaria de compartilhar esse momento e sentimentos gerados com outros negros, para ser mais exata com meninas negras, pois o tratamento dado às meninas era bem distinto do que ocorria com os meninos negros, segundo ela. Ser mulher e negra na nossa sociedade é experimentar "preconceito ainda muito maior", não apenas o preconceito, mas a discriminação também. De acordo com seu depoimento: "eu sofria mais preconceito que meu irmão e eu não sabia porque, pois meu irmão mais novo que eu também estudava na mesma escola".

Não entraremos na discussão sobre quem sofre mais preconceito, se homens ou mulheres negras, porque acreditamos inegavelmente que são as mulheres, mas gostaríamos de ressaltar que os jovens negros também passam por muitas situações negativas de preconceito e discriminação e buscam estratégias para a construção de si.

Em uma das experiências educativas que tivemos na educação superior discutindo relações étnico-raciais, foi possível observar e mapear algumas dessas táticas utilizadas para fugir da "guerra" simbolicamente instalada em nossas escolas. Em um exercício de autoidentificação, solicitamos aos educandos que dissessem como se afirmavam racial e etnicamente e justificassem a resposta. Surgiram várias categorias, mas uma delas se destacou: um dos jovens disse que era marrom, por conta da tonalidade da pele.

Apesar das brincadeiras e risos frouxos pelas diversas categorias acionadas, a fala daquele educando permaneceu em nossas cabeças. Quando estávamos quase ao final do curso, o jovem nos chamou e explicou porque ele se considerava marrom. A ideia da categoria marrom surgiu no período em que cursava a educação básica, como uma contraargumentação às investidas de seus colegas que o chamavam de "preto retinto, preto da senzala, 
urubu". Como os apelidos geravam muita chacota, dor e sofrimento, num determinado dia ele resolveu fazer uma discussão com os colegas para mostrar que eles estavam errados. Pegou vários objetos de cor preta e marrom e os comparou à sua cor para "provar" que era marrom e, portanto, não era preto. Podemos destacar a partir dessas narrativas que 0 preconceito racial nas trajetórias de vida de estudantes negros e indígenas foi uma construção social brasileiro, conforme afirma a autora seguinte,

No caso do negro brasileiro, a classificação e a hierarquização racial hoje existentes, construídas na efervescência das relações sociais e no contexto da escravidão e do racismo, passaram a regular as relações entre negros e brancos como mais uma lógica desenvolvida no interior da nossa sociedade. Uma vez constituídas, são introjetadas nos indivíduos negros e brancos pela cultura. Somos educados pelo meio sociocultural a enxergar certas diferenças, as quais fazem parte de um sistema de representações construído socialmente por meio de tensões, conflitos, acordos e negociações sociais. (GOMES, 2003, p. 76-77).

Também buscamos em Costa (1983) a compreensão dos estudos sobre ser negro na sociedade brasileira. Para esse autor, a violência é a pedra de toque, núcleo central do problema abordado: "Ser Negro é ser violentado de forma constante, contínua e cruel, sem pausa ou repouso, por uma dupla injunção: a de encarnar o corpo e os ideais de Ego do sujeito branco e a de recusar, nega e anula a presença do corpo negro" (COSTA, 1983, p. 02).

O racismo brasileiro impõe as representações do corpo negro como objeto de inferioridade e, nesse caso, leva ao negro se valer do seu próprio corpo para desmistificar os estereótipos a ele empregados, visto que conseguiu fazer com que o preconceito e a discriminação pela cor/raça não recaíssem mais sobre si: "foi como eu consegui fazer com que eles me deixassem em paz", argumentou Marrom. Geralmente, ao usar essa estratégia, nega-se a verdade de sua existência, de seu corpo negro, e encarcera ainda mais os sujeitos na ideologia do branqueamento. Entretanto, segundo esse educador negro, ele sabia que não estava negando a sua negritude, mas utilizando mecanismos para se afastar dos estereótipos raciais negativos que tanto se impunham a ele: "eu sempre soube que era negro; eu sei que sou! Mas ser preto na escola é bem diferente". Para ele, essa foi a estratégia de resistência aos preconceitos e discriminações sofridos no ambiente escolar.

É preciso levar em consideração que essa reflexão ocorreu a partir das discussões realizadas em sala, quando o educando pode pensar sobre sua identidade e analisar a forma como a manejou ao longo do tempo frente às diferentes situações, contextos e pessoas com quem entrou em contato, que resultaram em silêncios sobre suas identidades, invisibilizações no cenário político e social e não lugares para indígenas, negros e quilombolas na trajetória escolar. Como disse Dandara: "acredito também que o preconceito me prejudicou muito, pois o meu aprendizado foi tardio, aprendi a ler e escrever aos onze anos de idade" (educadora negra). Mas isso não prejudicou somente ela: há várias gerações de indígenas, negros, quilombolas e comunidades tradicionais que vêm tendo seu direito à educação, específica e diferenciada, violentamente lesado no território nacional.

Por isso o acesso ao ensino superior/educação diferenciada tem sido apontado pelos que ingressam na universidade como parte da luta para a garantia da especificidade nas escolas de suas comunidades e onde se fizerem presentes, mas também pela efetiva implementação das leis no. 10.639 e no. 11.645 na educação básica de todo o país, especialmente pelo fato de tratar-se de uma educação escolar constituída a partir da realidade em que está inserido o educando, que traz em suas narrativas e ações sua cultura, costumes e hábitos, que são trabalhados ao longo das atividades curriculares, reunindo discussões teóricas e os saberes que estes sujeitos trazem consigo com o objetivo de (des)construir conhecimentos numa perspectiva descolonial (FREIRE, 2014; BERNARDI; BERNARDI, 2017). 


\section{Universidade, educação diferenciada e seus significados}

Por educação diferenciada compreendese aquela que se propõe à escolarização de povos indígenas, quilombolas, negros e comunidades tradicionais, levando em consideração o contexto social, histórico e cultural específicos e pela qual se pretende a efetivação do diálogo entre as culturas e epistemologias dos diversos grupos envolvidos na relação social. Nesse sentido, é essencialmente uma educação política, na medida em que coloca em discussão outras possibilidades de interpretar e representar o mundo, retirando da episteme ocidental a universalidade de criar e dar sentido às coisas (LUCIANO, 2006).

Segundo Hall (2016, p. 317):
[...] Uma vez elaborada a
ideia de OCIDENTE, ela por
si só tornou-se produtiva.
Provocou efeitos reais:
possibilitou que pessoas
falassem sobre certas
coisas de certas maneiras.
Produziu conhecimento.
Tornou-se, duplamente, o
fator organizador em um
sistema de relações
globais de poder e o
conceito organizador ou
termos em uma forma
inteira de pensar e falar.

Uma das principais formas de resistência apontadas ao longo dos anos pelos diferentes sujeitos e coletividades em movimento no país tem sido a apropriação da escola, isto é, da educação escolar (LASMAR, 2005; 2009; SILVA, 1999). Como espaço de poder, a escola foi utilizada como elemento importante do projeto civilizacional ocorrido neste território, com vistas à transformação de indígenas e negros escravizados em mão de obra para erigir a nação brasileira.

A escola foi parte importante para a constituição de homogeneidades e hegemonias, relegando a diversidade à marginalização dos "guetos" e ao universo dos ambientes privados e domésticos, ou às reservas de áreas para se reproduzirem, dando visibilidade ao discurso da mestiçagem como mistura numa evidente estratégia de apagamentos e violações de direitos. Mas esses sujeitos não se deixaram dominar e exigiram do Estado brasileiro o direito diferenciado à educação, como informa uma de nossas interlocutoras:

Onde estamos é através
das lutas, as lutas viram as
conquistas e as conquistas
é esse espaço onde nós
estamos [a universidade].
Esse grupo aqui, e vocês
também, vão ter o mérito
de chegar até o final
também [...] o curso
[Etnodesenvolvimento] é
muito importante para
nossas vidas porque nós
somos pessoas da luta e
movimentos sociais e esse
espaço realmente é para
nós, para que nós
possamos somar o nosso
coletivo que tá esperando
por cada um de vocês que
tão aqui. Vocês vão ser os
multiplicadores desse
espaço que vocês vieram
buscar aqui (Anastácia,
educadora quilombola).

O relato é extremamente pertinente para compreendermos o significado do acesso à educação como uma conquista, produto da luta ${ }^{7}$ dos sujeitos históricos, ao mesmo tempo que servirá à luta, na medida em que há uma expectativa de que façam o movimento de ir e vir entre as bases dos movimentos, a universidade e novamente aos movimentos.

Além disso, Anastácia reitera o acesso à educação no Ensino Superior como espaço de representatividade dos sujeitos indígenas, negros, quilombolas e tantos outros que historicamente se constituíram na luta, pois sua entrada em hipótese alguma pode ser pensada como particular, de modo que a identidade está assentada em sentimentos de pertenças compartilhados pelo grupo, nunca individualmente.

Uma educação assentada na participação, no respeito à diferença e especificidade de cada sujeito, representante de seus coletivos de pertença, tendo como princípios epistemológicos a interculturalidade, como consta no Parecer MEC/CNE14/99 (BRASIL, 1999), e alternância pedagógica, com o intuito de promover ensino

\footnotetext{
${ }^{7}$ Luta, nesta discussão, está sendo apreendida como categoria que compreende a forma como os interlocutores organizaram e mobilizaram ações para a manutenção da alteridade em contextos, situações e relações sociais variadas.
} 
voltado à diversidade, para a formação de educadores para as escolas étnica e culturalmente diferenciadas (OLIVEIRA; PARENTE; DOMINGUES, 2017).

Educação no ensino superior pensada e concretizada a partir das realidades sóciohistóricas e culturais dos distintos povos e comunidades, construída com eles em busca do desvelamento das relações sociais de opressão e dominação a que estiveram/estão sujeitos (FREIRE, 2014). De uma educação que se faz na práxis, em que todos se educam porque estão pautados pela ideia de que o conhecimento não está encerrado na razão científica, respeitando os múltiplos tempos e saberes, com o intuito de produzir outros conhecimentos, pois tem por base a consciência de sua incompletude; portanto, intercultural por excelência - o que Sousa Santos (2001) chama hermenêutica diatópica.

Baseado na Pedagogia da Alternância ${ }^{8}$, o curso em análise foi pensado como educação diferenciada para público cuja presença pluralizasse as salas de aula, os corredores e os muros da instituição, mas acima de tudo como estratégia para trazer à tona a discussão sobre a diversidade sociocultural na universidade.

Trata-se de uma abordagem radicalmente diferente de educação escolar e requer estratégias específicas para realizar mudanças que não se resumem apenas a um currículo voltado ao conhecimento de áreas essenciais à elaboração de desenvolvimentos alternativos, mas que se referem também a conteúdos a serem trabalhados, à maneira como se discute e a como se encaminha a discussão.

Candau (2008) aponta algumas características sobre a perspectiva intercultural, que considera a mais adequada para a construção de sociedades democráticas e inclusivas em articulação com as políticas de igualdade e identidade, tais como: 1) a promoção de inter-relação entre diferentes grupos culturais de uma mesma sociedade; 2 ) o rompimento com a visão essencialista de culturas e identidades, concebendo-as de forma processual; 3) a

\footnotetext{
${ }^{8}$ A Pedagogia da Alternância foi adotada no Brasil a partir dos anos 1960 e aplicada, primeiramente, nas Escolas Famílias Agrícolas (EFAs) e Casas Familiares Rurais (CFRs). Tem por objetivo o desenvolvimento do processo de formação em tempos e espaços diferenciados, coadunando formação escolar e experiências de vida, é resultante de exercício contínuo que envolve também a formação de educandos e educadores. Para maiores esclarecimentos sobre o assunto, consultar Ribeiro (2008); Teixeira, Bernartt e Trindade (2008); Cordeiro, Reis e Hage (2011); e Martins (2012).
}

afirmação de que em nossas sociedades os processos de hibridização cultural são intensos e mobilizadores de identidades em construção; 4) a consciência de que as relações culturais são construídas na história e eivadas de poder hierarquicamente estabelecido, imbuído de preconceito e de discriminação, por consequência; e 5) o vínculo hoje entre diferença e desigualdade.

Afirmar a existência dessa relação é o primeiro passo para a busca de uma educação para o reconhecimento do outro, tendo por desafios: a) desconstruir o que foi socialmente construído e reificado em nossa sociedade; b) articular o direito à igualdade e à diferença nas políticas educativas e práticas pedagógicas, em que "[...] a igualdade se explicite nas diferenças assumidas como referência comum" (CANDAU, 2008 , p. 53); c) valorizar os processos de identidades culturais, construídas individual e coletivamente; d) promover experiências de interação para suscitar a posição de relativização no mundo; e e) favorecer processos de "empoderamento" de atores sociais e coletividades vulnerabilizados social, cultural e etnicamente, com vistas à ação política para o rompimento das relações de submissão desiguais de poder (CANDAU, 2008, p. 53-54).

Aqui há um elemento importante a ser considerado: a educação diferenciada está sempre voltada à transformação e talvez isso explique muitos dos desafios que temos em sua implantação, porque está comprometida com os grupos que tiveram seus direitos de acesso negados, como relata Anastácia:
Anteriormente, a Universidade era só para os filhos dos senhores, nós não tínhamos espaço e oportunidade. Hoje nós temos, mas não diz que o Estado é bom. Isso é uma dívida que o Estado tem conosco, povo negro, quilombola, indígena, agricultor, pescador; todos nós, movimentos sociais.

O acesso à educação, por sua vez, pretende gerar no outro o compromisso para a reorganização das ordens estabelecidas em todos os âmbitos de atuação, para descortinar e visibilizar a condição étnica, racial e cultural diferenciada em nossa sociedade: "a nossa sociedade precisa dessa ajuda nossa para tomar, 
para contribuir, para expressar lá fora a invisibilidade sobre o que é ser quilombola" (Anastácia, educadora quilombola), estendendose isso para indígena, negra, ribeirinho/a, agricultor/a, dentre outros.

\section{Estar na Universidade/educação diferenciada}

Essa pluralidade de sujeitos cultural, étnica e racialmente diferentes na universidade, aliançados pelo compromisso social e politicamente estabelecidos em seus grupos e coletividades de pertença, faz com que a universidade chegue em vários municípios ao mesmo tempo, pois temos educandos em diferentes regiões do estado do Pará. Estamos falando das regiões do Tapajós, Transamazônica e Xingu, Tocantina, Bragantina, Salgado Paraense e Marajó, dos campos e das florestas.

$O$ acesso ao Ensino Superior em cursos diferenciados tem se apresentado não somente como a conquista do direito à educação escolar, por muito tempo negado aos povos indígenas, quilombolas, negros e comunidades tradicionais, mas também como o reconhecimento identitário desses grupos por parte do Estado brasileiro (PARENTE, 2016), o que Luciano (2006) denomina dupla cidadania, pois a conquista do direito à educação escolar superior se deu, na UFPA, em paralelo ao reconhecimento da diferença e da especificidade no processo de seleção para esses sujeitos coletivos de direito.

Os estudos de Tardif (2010) sobre a formação de professores nos leva pensar que a formação em nível superior fundamentada na ética e estética da diferença pode desconstruir valores arraigados de preconceitos, criar processos de identidade com sentidos de pertença e com pesos políticos de pedagogias de resistências mediadas por práticas que agem na contra mão dos sofrimentos vividos pelos docentes. Vamos transcrever nesse artigo os pressupostos do autor tendo em vista a história de vida dos docentes, seus saberes e processos de formação em convergência com o esquema.

Os saberes dos professores

\begin{tabular}{|l|l|l|}
\hline \multicolumn{1}{|c|}{ Saberes dos professores } & \multicolumn{1}{|c|}{ Fontes sociais de aquisição } & $\begin{array}{l}\text { Modos de integração no trabalho } \\
\text { docente }\end{array}$ \\
\hline $\begin{array}{l}\text { Saberes pessoais dos } \\
\text { professores }\end{array}$ & $\begin{array}{l}\text { A família, o ambiente de vida, a } \\
\text { educação no sentido lato, etc. }\end{array}$ & $\begin{array}{l}\text { Pela história de vida e pela } \\
\text { socialização primária }\end{array}$ \\
\hline $\begin{array}{l}\text { Saberes provenientes da } \\
\text { formação escolar anterior }\end{array}$ & $\begin{array}{l}\text { A escola primária e secundária, } \\
\text { os estudos pós-secundários não } \\
\text { especializados, etc. }\end{array}$ & $\begin{array}{l}\text { Pela formação e pela socialização } \\
\text { pré-profissionais }\end{array}$ \\
\hline $\begin{array}{l}\text { Saberes provenientes da } \\
\text { formação profissional para o } \\
\text { magistério }\end{array}$ & $\begin{array}{l}\text { Os estabelecimentos de } \\
\text { formação de professores, os } \\
\text { estágios, os cursos de } \\
\text { reciclagem, etc. }\end{array}$ & $\begin{array}{l}\text { Pela formação e pela socialização } \\
\text { profissionais nas instituições de } \\
\text { formação de professores }\end{array}$ \\
\hline $\begin{array}{l}\text { Saberes provenientes dos } \\
\text { programas e livros didáticos } \\
\text { usados no trabalho }\end{array}$ & $\begin{array}{l}\text { A utilização das "ferramentas" } \\
\text { dos professores: programas, } \\
\text { livros didáticos, cadernos de } \\
\text { exercícios, fichas, etc. }\end{array}$ & $\begin{array}{l}\text { Pela utilização das "ferramentas" } \\
\text { de trabalho, sua adaptação às } \\
\text { tarefas }\end{array}$ \\
\hline $\begin{array}{l}\text { Saberes provenientes de sua } \\
\text { própria experiência na } \\
\text { profissão, na sala de aula e na } \\
\text { escola }\end{array}$ & $\begin{array}{l}\text { A prática do ofício na escola e } \\
\text { na sala de aula, a experiência } \\
\text { dos pares, etc. }\end{array}$ & $\begin{array}{l}\text { Pela prática do trabalho e pela } \\
\text { socialização profissional }\end{array}$ \\
\hline
\end{tabular}

Fonte: adaptado de Tardif (2010, p. 63).

Os saberes que advêm da formação profissional pela educação diferenciada tem sido apropriada como uma possibilidade de refletir sobre si, já que foi por ela que esses indivíduos tiveram condições para a discussão sobre temas pertinentes à diversidade cultural e em dialogicidade com outras lógicas de pensamento. Por exemplo, Zumbi comenta que até a entrada na universidade não tinha sentido o preconceito e a discriminação em relação à sua cor/raça, apesar de ter passado por muitas situações constrangedoras que enveredaram em muito 
para seu sofrimento individual. Foi somente na universidade, pelas discussões empreendidas no âmbito de sua formação no curso de Etnodesenvolvimento, que ele tomou consciência das situações de preconceito e discriminação experimentados subjetivamente porque as associou à questão racial vivida por negros e quilombolas ao longo da história.

Por isso chama atenção para o papel político de negros e quilombolas, formados em nível de graduação e pós-graduação ${ }^{9}$ para a discussão nas escolas de educação básica e também nos movimentos sociais e lugares, uma vez que a presença negra e quilombola é sempre uma representação política em detrimento do lugar que ocupa, e se faz necessária a autoconsciência desse processo para o enfrentamento junto ao Estado, como explicita Zumbi:

Nós temos a[s] lei[s],
agora temos que lutar
para que em todas as
escolas elas sejam
trabalhadas, porque na
realidade, eu já fui escutar
bem essa versão
[preconceito na
discriminação]
universidade, que na
própria escola do meu
município do Ensino
Médio não existia; já foi
entender o que era isso na
universidade. Então é uma
preparação que é o tempo
todo, nós temos que estar
alerta, nós estamos aqui,
vocês estão fazendo. Esse
espaço é nosso, é de vocês
(Educador negro e
quilombola).

A narrativa não é exclusiva dos negros e quilombolas; indígenas e outros sujeitos coletivos sempre relatam seu compromisso no retorno para a comunidade, que se dá por meio do regresso para assumir cargos públicos e/ou pela luta direta ou indireta no movimento, porque acreditam que seu compromisso também ocorre

\footnotetext{
${ }^{9}$ Quase todos os 10 quilombolas formados na primeira turma do curso concluíram ou estão realizando pós-graduação, especializando-se nas discussões sobre as leis no. 10.639/03 e no. 11.645/08 e Educação do Campo. Os demais formados, sendo eles indígenas, negros, agricultores familiares e ribeirinhos, também seguiram os mesmos caminhos e trilharam a especialização em Direitos Humanos e Diversidade e Educação, Diversidade e Sociedade, todas oferecidas pela UFPA, campi de Belém e Altamira.
}

no desvelamento das situações de apagamento cultural e de representatividade que todo indígena, quilombola, negro e negra, dentre tantos deles, podem impor com sua presença física em diferentes lugares.

\section{Tecendo algumas considerações: a emergência prática das leis 10.639/03 e 11.645/08}

Os próprios educandos em formação percebem e evidenciam nas narrativas a lacuna deixada pela ausência da discussão sobre diversidade na educação básica, mesmo havendo leis desde o início dos anos 2000 que tornaram o debate sobre história e cultura e povos negros, quilombolas e indígenas obrigatórios. No momento em que entraram na universidade, em cursos voltados para o diálogo com a diferença, eles se dão conta da deficiente discussão sobre esses temas na educação básica a que tiveram acesso e o quanto isso prejudicou a afirmação étnica, racial e coletiva de seus povos e comunidades.

Por isso, acreditamos que a formação de professores permite não só preencher a demanda por quantitativo de profissionais da educação, mas de professores qualificados para o debate sobre a diversidade, oriundos de cursos diferenciados e assentados na discussão política sobre o seu lugar no processo de escolarização e de fortalecimento de sujeitos e comunidades na busca por educação intercultural e específica nas escolas indígenas, quilombolas e de comunidades tradicionais. Com isso, eles não apenas têm a possibilidade de discutir sobre os marcadores sociais da diferença, mas acima de tudo a se imporem, a partir de sua representatividade como parte da diferença num lugar identificado e reconhecido de forma positiva em nossa sociedade.

Nota-se pelas trajetórias dos sujeitos negros, quilombolas e indígenas que, em detrimento da existência das leis no. 10.639 e no. 11.645 e de elas terem sido promulgadas e estarem em vigência desde 2003 e 2008, respectivamente, a formação na educação básica ainda carece de discussão sobre marcadores sociais de diferença que ensejam a diversidade de nosso país, relegando aos jovens o fardo de trajetórias que narram dor e sofrimento por conta de preconceito, discriminação e racismo sofridos.

Nesse sentido, o acesso a cursos diferenciados como o de Etnodesenvolvimento tem permitido desvelar situações subjetivas e 
recolocá-las sob o ponto de vista das coletividades etnicamente diferenciadas, o que possibilitou aos sujeitos perceberem a lógica do "racismo à brasileira" e reconhecessem tratamentos desrespeitosos e individuais como preconceito/discriminação de etnia e raça.

$\mathrm{Na}$ formação de professores, os quais carregam nos corpos, mentalidades e epistemologias de mundo, a perspectiva da educação para a diversidade tem sido observada na prática como estratégica desses docentes e das comunidades para o exercício do respeito à diferença. Além disso, esses indivíduos têm sido representados como professores, pesquisadores, articuladores políticos, dentre outras funções e papéis sociais.

Os egressos dos cursos diferenciados da UFPA têm continuado sua trajetória nesse caminho, continuando na pós-graduação e na efetividade de sua prática em sala de aula ou em movimentos a que estão vinculados para a luta em torno da educação diferenciada, seguindo por vários caminhos, como: [1] trabalhando com projetos de educação, como Educação de Jovens e Adultos (EJA), Campos e Florestas e Indígenas; [2] conquistando espaço para trabalhar nas escolas de suas comunidades; e [3] atuando nas associações e entidades políticas, assim como na gestão da educação escolar de seus povos e comunidades, haja vista que a luta não pode cessar enquanto seus direitos não estiverem completamente garantidos e o respeito à diversidade não se tornar o mote da educação e da vida em sociedade.

No momento em que as leis conquistadas estão sendo violadas institucionalmente, reiterar os impactos negativos da educação escolar universal e homogeneizante nos permite reafirmar a importância da diferença e de sua manutenção, e isso se dá essencialmente pela garantia das políticas afirmativas para povos indígenas, quilombolas, negros e comunidades tradicionais na educação, ${ }^{10}$ pois: "é uma luta que nós temos que lutar porque ela existe, mas não é respeitada. [...] A melhora para o nosso país é só através de educação. Então bora chamar esse pessoal para nós ocuparmos esse espaço que é nosso" (Zumbi, educador negro e quilombola).

Portanto, a ressignificação da escolarização por indígenas, negros e

\footnotetext{
10 Para discussão mais aprofundada sobre o acesso ao Ensino Superior e a reafirmação da diferença étnica entre os povos indígenas que vivem na cidade a partir da experiência construída de educação diferenciada na UFPA, consultar Parente (2015).
}

quilombolas tem dado mostras de que é uma das vias mais significativas para a transformação pretendida por quem investe esforços nesse caminho. Essa é uma reflexão importante a ser feita em tempos de desmontes de importantes direitos sociais, civis e políticos, como as políticas públicas voltadas para o respeito à diversidade.

\section{REFERÊNCIAS}

ALMEIDA, Alfredo Wagner Berno de. Terras de quilombos, terras indígenas, "babaçuais livre", "castanhais do povo", faxinais e fundos de pasto: terras tradicionalmente ocupadas. 2. ed. Manaus: PGSCA -UFAM, 2008.

BARBOSA, Lívia. O jeitinho e "você sabe com quem está falando?": uma comparação entre dois dramas sociais. In: BARBOSA, Lívia. O Jeitinho Brasileiro: a arte de ser mais igual do que os outros. Rio de Janeiro: Elsevier, 2006. p. 91-101.

BARTH, Fredrik. Os grupos étnicos e suas Fronteiras. In: LASK, Tomke (Org.). O guru, o iniciador e outras variações antropológicas. Rio de Janeiro: Contra Capa, 2000. p. 25-67.

BELTRÃO, Jane; LOPES, Rhuan. Diásporas, homogeneidades e pertenças entre os Tembé Tenetehara de Santa Maria. Aceno, Vol. 1, N. 1, p. 123-143. Jan. a Jul. de 2014.

BENBASSA, Esther. Dictionaire des racismes, d'exclusion et des discriminations. Rodesa/Espanha: Larousse, 2010.

BERNARDI, Luci Teresinha Marchiori dos Santos; BERNARDI, Luzane Moraes. Educação Indígena: formação de professor em uma perspectiva emancipatória. Educação em Foco, v., n. 32, p. 61-78, Set./Dez. 2017.

BHABHA, Homi. O Local da Cultura. Tradução de: Myriam Ávila; Eliana Lourenço de Lima Reis; Gláucia Renate Gonçalves. Belo Horizonte: Editora UFMG, 2005.

BOURDIEU, Pierre. A Ilusão Biográfica. In: AMADO, Janaína; FERREIRA, Marieta Moraes. Usos \& abusos da história oral. Rio de Janeiro: Editora da Fundação Getúlio Vargas, 1998. p. 183-191. 
BRASIL. Parecer do Conselho Nacional de Educação, n. 14 de 10/11/1999. Brasília: CNE/CEB, 1999.

BRASIL. Presidência da República. Casa Civil. Subchefia para Assuntos Jurídicos. Lei no 10.639, de 9 de janeiro de 2003. Altera a Lei no 9.394, de 20 de dezembro de 1996, que estabelece as diretrizes e bases da educação nacional, para incluir no currículo oficial da Rede de Ensino a obrigatoriedade da temática "História e Cultura Afro-Brasileira", e dá outras providências. Diário Oficial da União, Brasília, 10 jan. 2003.

BRASIL. Presidência da República. Casa Civil. Subchefia para Assuntos Jurídicos. Lei no 11.645, de 10 de março de 2008. Altera a Lei no 9.394, de 20 de dezembro de 1996, modificada pela Lei no 10.639, de 9 de janeiro de 2003, que estabelece as diretrizes e bases da educação nacional, para incluir no currículo oficial da rede de ensino a obrigatoriedade da temática "História e Cultura Afro-Brasileira e Indígena". Diário Oficial da União, Brasília, 11 mar. 2008.

CANDAU, Vera Maria. Direitos humanos, educação e interculturalidade: as tensões entre igualdade e diferença. Revista Brasileira de Educação, v.13, n.37, p. 45-56, 2008. DOI:10.1590/S1413-24782008000100005.

Disponível em: http://www.scielo.br/scielo.php?script=sci_arttex t\&pid=S1413-

$24782008000100005 \&$ Ing=pt\&tlng=pt. Acesso em: 10 de junho de 2018.

CORDEIRO, Georgina N. K.; REIS, Neila da Silva; HAGE, Salomão Mufarrej. Pedagogia da alternância e seus desafios para assegurar a formação humana dos sujeitos e a sustentabilidade do campo. Em Aberto, Brasília, v. 24, n.85, p. 115-125, 2011.

COSTA, Jurandir Freire. Da cor ao corpo: a violência do racismo. (Prefácio). In: SOUSA, Neusa Santos. Tornar-se negro: as vicissitudes da identidade do negro brasileiro em ascensão social. Rio de Janeiro: Graal, 1983.

FREIRE, Paulo. Pedagogia do Oprimido. Rio de Janeiro: Paz e Terra, 2014.
GOMES, Nilma. Lino. Cultura negra e educação. Revista brasileira de Educação, n.23, Maio/Jun./Jul./Ago., 2003. DOI: 10.1590/S141324782003000200006 Disponível em: http://www.scielo.br/scielo.php?script=sci_arttex t\&pid=S1413-

$24782003000200006 \& \operatorname{lng}=p t \& t \operatorname{lng}=$ pt. $\quad$ Acesso em: 13 de junho de 2018.

GOMES, Nilma. Lino.; SILVA, Petronilha. Beatriz. Gonçalves e. (Org.) Experiências étnico-culturais para a formação de professores. 2. ed. Belo Horizonte: Autêntica, 2006.

GLUCKMAN, Max. Análise de uma situação social na Zululândia moderna. In: FELDMAN-BIANCO, Bela (Organizadora). Antropologia das Sociedades Contemporâneas: métodos. São Paulo: Editora UNESP, 2010. p. 237-364.

HALL, Stuart. Da Diáspora. Identidades e mediações culturais. Belo Horizonte: Editora UFMG, 2003.

HALL, Stuart. O Ocidente e o Resto: discurso e poder. Projeto História, São Paulo, n. 56, p. 314361, Mai-Ago 2016.

HYPOLITO, Alváro. Moreira. et al. Trabalho docente, profissionalização e identidade: contribuições para a constituição de um campo de estudo. Educação em Revista, Belo Horizonte, n. 37, p. 123-138, jul. 2003.

LASMAR, Cristiane. De Volta ao Lago de Leite: gênero e transformação no Alto Rio Negro. São Paulo: UNESP: ISA; Rio de Janeiro: NUTI, 2005.

LASMAR, Cristiane. Conhecer para transformar: os índios do rio Uaupés (Alto Rio Negro) e a educação escolar. Tellus, ano 9, n. 16, p. 11-33, jan./jun. 2009.

LUCIANO, Gersem dos Santos. O índio brasileiro: - que você precisa saber sobre os povos indígenas no Brasil de hoje. Brasília: Ministério da Educação, Secretaria de Educação Continuada, Alfabetização e Diversidade; LACED/ Museu Nacional, 2006.

MARTINS, José Fernando. A pedagogia da terra: os sujeitos do campo e do ensino superior. Educação, Sociedade e Cultura, n.36, p. 103-119, 2012. 
NOGUEIRA, O. Preconceito racial de marca e preconceito racial de origem: sugestão de um quadro de referência para a interpretação do material sobre relações raciais no Brasil. In: Tempo Social, Revista de Sociologia da USP, v. 19, n.1. 2006.2 DOI:10.1590/S0103$20702007000100015 . \quad$ Disponível em: http://www.scielo.br/scielo.php?script=sci_arttex t\&pid=S0103-

20702007000100015\&lng=pt\&nrm=iso\&tlng=pt.

Acesso em: 25 de junho de 2018.

OLIVEIRA, Assis da Costa; PARENTE, Francilene de Aguiar; DOMINGUES, William C. Lopes. Pedagogia $\mathrm{da}$ Alternância $\mathrm{e}(\mathrm{m})$ Etnodesenvolvimento: realidade e desafios. Educação e Realidade, ISSN 0100-3143 (Versão impressa) v.42, p. 1545-1565 2017.

PARENTE, Francilene de Aguiar. "Eles são indígenas $e$ nós também": pertenças $\mathrm{e}$ identidades étnicas entre Xypaia e Kuruaya em Altamira/Pará. 281 f. 2016. Tese (Doutorado em Antropologia - PPGA) - Universidade Federal do Pará (UFPA), Belém, 2016.

PARENTE, Francilene de Aguiar.. Educação superior diferenciada e reelaboração da diferença entre indígenas na UFPA. In: OLIVEIRA, Assis da Costa; BELTRÃO, Jane Felipe. Etnodesenvolvimento \& Universidade: formação acadêmica para povos indígenas e comunidades tradicionais. Belém: Editora Santa Cruz, 2015. p 171-190.

SILVA, Rosa Helena Dias da. A Autonomia como Valor e Articulação de Possibilidades: o movimento dos professores indígenas do Amazonas, de Roraima e do Acre e a Construção de uma Política de Educação Escolar Indígena. Cadernos Cedes, v.19, n. 49, dez. 1999. Disponível em:

www.anped.org.br/reunioes/25/luciolapessoacav alcantet08.rtf. Acesso em: 20 junho 2018.

RIBEIRO, Marlene. Pedagogia da alternância na educação rural/do campo: projetos em disputa. Educação e Pesquisa, v.34, n.1, p. 27- 45, 2008. DOI: $\quad 10.1590 / S 1517-97022008000100003$. Acesso em: 10 de julho de 2018.
SOUSA SANTOS, Boaventura de. Pela Mão de Alice. O social e o político na pós-modernidade. São Paulo: Editora Cortez, 2001.

TARDIF, M. Saberes docentes e formação profissional. 10. ed. Petrópolis, Rio de Janeiro: Vozes, 2010.

TEIXEIRA, Edival Sebastião; BERNARTT, Maria de Lourdes; TRINDADE, Glademir Alves. Estudos sobre pedagogia da alternância no Brasil: revisão de literatura e perspectivas para a pesquisa. Educação e Pesquisa, v.34, n.2, p. 227-242, 2008. DOI: $\quad 10.1590 /$ S1517-97022008000200002. Disponível em: http://www.scielo.br/scielo.php?script=sci_arttex $\mathrm{t} \& \mathrm{pid}=\mathrm{S} 1517-$

$97022008000200002 \& \operatorname{lng}=p t \&$ tlng=pt. $\quad$ Acesso em: 1 de junho de 2018.

TODOROV, Tzvetan. A conquista da América. A questão do outro. São Paulo: Martins Fontes, 1993.

UFPA. Resolução N. 3.860 DE 22 de maio de 2009. Belém: CONSEPE, 2009.

UFPA. Projeto Pedagógico do Curso de Licenciatura $e$ Bacharelado em Etnodesenvolvimento. Belém: CONSEPE, 2009.

WEBER, Max. Relações comunitárias étnicas. In: WEBER, Max. Economia e Sociedade: fundamentos da sociologia compreensiva. Brasília: Ed. Universidade de Brasília, 2014. p. 267-277. Vol. I.

Recebido para avaliação: 15/10/2018

Revisado em: 03/12/2018

Aceite Final: 03/12/2018 